\title{
GENERALIZED LOCALLY PAIRWISE CLOSED SETS ON BITOPOLOGICAL SPACES AND SOME OF ITS PROPERTIES
}

\author{
A. Kandil ${ }^{a}$, O. A. E. Tantawy ${ }^{b}$, S. A. El-Sheikh ${ }^{c}$ and E. A. Shalaby ${ }^{c} *$ \\ ${ }^{a}$ Mathematics Department, Faculty of Science, Helwan University, Helwan, Egypt. \\ ${ }^{b}$ Mathematics Department, Faculty of Science, Zagazig University, Zagazig, Egypt. \\ ${ }^{c}$ Mathematics Department, Faculty of Education, Ain Shams University, Cairo, Egypt.
}

Received 6/5/2017 Revised 29/7/2017_ Accepted 13/8/2017

\begin{abstract}
In this paper, we introduce the notions of generalized locally pairwise closed sets, generalized locally pairwise closed star sets, generalized locally pairwise closed star star sets on bitopological spaces and study some of their properties. The properties of the space $\left(X, \tau_{1}, \tau_{2}\right)$ are studied through the study of the space $\left(X, \tau_{12}\right)$ which is a supra topology associated to the bitopological space $\left(X, \tau_{1}, \tau_{2}\right)$. Also, characterization of these sets have obtained. Finally, we introduce the notions of $G L P C-$ ( resp. $G L P C^{*}, G L P C^{* *}$ ) (continuous) irresolute functions which based on these sets and study some of their properties.
\end{abstract}

2010 Mathematics Subject Classification. 54A05, 54XX, 06D72, 54A40, 54E55.

Keywords: Generalized locally pairwise closed sets, Generalized locally pairwise open sets, Generalized locally pairwise closed star set, Generalized locally pairwise closed star star set.

\section{Introduction}

(Levine, 1970) [1] introduced the fundamental concept of generalized closed sets. He defined a set $A$ to be generalized closed if its closure contained in every open superset of $A$. A bitopological space $\left(X, \tau_{1}, \tau_{2}\right)$ was introduced by Kelly [2] in 1963, as a method of generalizes topological space $(X, \tau)$. Every bitopological space $\left(X, \tau_{1}, \tau_{2}\right)$ can be regarded as a topological space $(X, \tau)$ if $\tau_{1}=\tau_{2}=\tau$. In 1983, Mashhor et al. [3] introduced supra topological spaces by dropping only the intersection condition. In [4] Kandil et al. generated a supra topological space ( $\left.X, \tau_{12}\right)$ from the bitopological space $\left(X, \tau_{1}, \tau_{2}\right)$ and they studied some properties of the space $\left(X, \tau_{1}, \tau_{2}\right)$ via properties of the associated space $\left(X, \tau_{12}\right)$. Thereafter, a large number of papers have been written to generalize topological concepts to bitopological setting [4-9].

In general topology at 1988, Ganstern and Reilly [10] was studied the concepts of locally closed $(L C)$ set and locally closed continuous ( $L C$ continuous) functions. At 1996 Krishan, Palaniappan and Haruo [11] were studied the concept of generalized locally closed sets, generalized locally closed star sets, generalized locally closed star star sets and generalized locally closed continuous (GLC-continuous) functions. In this paper we introduce the notion of generalized locally pairwise closed sets, generalized locally pairwise closed star and generalized locally pairwise closed star star and study some of their properties. Also, we have used the previous concepts to define and study the concept of pairwise-submaximal and generalized pairwise submaximal P- submaximal. Finally,we study the concept of generalized locally pairwise closed (GLPC-) functions and some of their properties.

\section{Preliminaries}

This section contains the basic properties of generalized pairwise closed sets, generalized pairwise open sets, supra topological spaces and bitopological spaces.

Definition 2.1. [2] A bitopological spaces (briefly, bts) is a triple $\left(X, \tau_{1}, \tau_{2}\right)$ where $\tau_{1}$ and $\tau_{2}$ are arbitrary topologies on $X$.

\footnotetext{
${ }^{*}$ Corresponding author.

Name: Eman Al-shahat Ahmed Ali Shalaby

E-mail address:e.shalaby78@gmail.com
} 
Definition 2.2. [6]. Let $\left(X, \tau_{1}, \tau_{2}\right)$ be a bitopological space. Then, $A \subseteq X$ is said to be pairwise open (briefly, P-open) if $A=U_{1} \cup U_{2}, U_{i} \in \tau_{i}$, $(i=1,2)$. A set $A$ is called a P-closed if its complement $A^{c}$ is P-open.

Note that the notion of $P$-open sets as well as P-closed sets has studied in [4,12] under the name of $P^{*}$-open and $P^{*}$-closed.

Definition 2.3. [13]. A family $\eta \subseteq P(X)$ is said to be a supra topology if $\eta$ contains $X, \phi$ and closed under arbitrary union. The elements of $\eta$ are said to be supra open sets and their complements are said to be supra closed sets. The complement of any $A \subseteq X$, denoted by $A^{c}$.

Proposition 2.1. [12] Let $\left(X, \tau_{1}, \tau_{2}\right)$ be a bts. The family of all P-open subsets of $X$, denoted by $\tau_{12}$ is a supra topology on $X$ and $\left(X, \tau_{12}\right)$ is the supra topological space associated to the bts $\left(X, \tau_{1}, \tau_{2}\right)$.

Definition 2.4. [4]. An operator $C: P(X) \longrightarrow P(X)$ is a supra closure operator if it satisfies the following conditions for all A, $B \subseteq X$.

1. $C(\phi)=\phi$.

2. $A \subseteq C(A)$.

3. $C(A \cup B) \supseteq C(A) \cup C(B)$.

4. $C(C(A))=C(A)$.

Proposition 2.2. [12]. Let $\left(X, \tau_{1}, \tau_{2}\right)$ be a bts. Then, the operator cl $12: P(X) \longrightarrow P(X)$ defined by cl cl $_{12}(A)=\bar{A}^{1} \cap \bar{A}^{2}$, is a supra closure operator such that $\tau_{12}=\left\{A \subseteq X: \operatorname{cl}_{12}\left(A^{c}\right)=A^{c}\right\}$ where $\bar{A}^{i}$ is the closure of $A$ with respect to $\tau_{i}$ and $i=1,2$.

Proposition 2.3. [12]. Let $\left(X, \tau_{1}, \tau_{2}\right)$ be a bts. Then, the operator int ${ }_{12}: P(X) \longrightarrow P(X)$ defined by, int $12(A)=A^{o 1} \cup A^{o 2}$ is a supra interior operator such that $\tau_{12}=\left\{A \subseteq X:\right.$ int $\left._{12}(A)=A\right\}$, where $A^{o i},(i=1,2)$ is the $\tau_{i}$-interior with respect to $\tau_{i}$.

Proposition 2.4. [12]. Let $\left(X, \tau_{1}, \tau_{2}\right)$ be a bts and $A \subseteq X$. Then

1. $\tau_{1}, \tau_{2} \subseteq \tau_{12}$.

2. $\operatorname{cl}_{12}(A)=X \backslash \operatorname{int}_{12}(X \backslash A)$.

3. $\operatorname{int}_{12}(A)=X \backslash \operatorname{cl}_{12}(X \backslash A)$.

4. $A$ is $P$-open $\Leftrightarrow A=\operatorname{int}_{12}(A)$.

5. $A$ is $P$-closed $\Leftrightarrow A=\operatorname{cl}_{12}(A)$.

Definition 2.5. [4]. A mapping $f:\left(X, \tau_{1}, \tau_{2}\right) \longrightarrow\left(Y, \gamma_{1}, \gamma_{2}\right)$ is said to be $P^{*}-$ continuous function $\left(\right.$ briefly, $P^{*}$-cts $)$ if $f^{-1}(B) \in \tau_{12}$ for all $B \in \gamma_{12}$.

Definition 2.6. [4]. A mapping $f:\left(X, \tau_{1}, \tau_{2}\right) \longrightarrow\left(Y, \gamma_{1}, \gamma_{2}\right)$ is said to be $P^{*}-$ closed $\left(P^{*}\right.$-open) if $f(A)$ is $\gamma_{12}-$ closed (open) set on $Y$ for all $\tau_{12}$-closed (open) set $A$ in $X$.

Definition 2.7. [14] Let $\left(X, \tau_{1}, \tau_{2}\right)$ be a bts and $\left(X, \tau_{12}\right)$ its associated supra topological space. Then, $A \subseteq X$ is called a generalized pairwise closed set (briefly, gp-closed) if $\operatorname{cl}_{12}(A) \subseteq O$ whenever $A \subseteq O, O$ is a P-open.

Theorem 2.1. [14] $A$ set $A$ is a gp-closed set if and only if $c_{12}(A) \backslash A$ contains no non empty P-closed sets.

Corollary 2.1. [14] Let $A$ is a gp-closed set. Then, $A$ is $P$-closed if and only if $c_{12}(A) \backslash A$ is a P-closed set.

Remark 2.1. [14]

1. If $A$ is $P$-closed set, then $A$ is gp-closed set.

2. If $A$ and $B$ are gp-closed sets, then $A \cup B$ and $A \cap B$ are not necessary gp-closed set.

Definition 2.8. [14] Let $\left(X, \tau_{1}, \tau_{2}\right)$ be a bts, $A \subseteq X$ and $\left(A,\left.\tau_{1}\right|_{A},\left.\tau_{2}\right|_{A}\right)$ be a bitopological subspace of $\left(X, \tau_{1}, \tau_{2}\right)$. The collection $\tau_{12}(A)$ is defined as a following: $\tau_{12}(A)=\left.\left.\tau_{1}\right|_{A} \sqcup \tau_{2}\right|_{A}=\left\{U_{1} \cup U_{2}:\left.U_{1} \in \tau_{1}\right|_{A},\left.U_{2} \in \tau_{2}\right|_{A}\right\}$ such that $\left.\tau_{i}\right|_{A}=\left\{A \cap U_{i}: U_{i} \in \tau_{i}, i=1,2\right\}$.

Theorem 2.2. [14] Let $\left(X, \tau_{1}, \tau_{2}\right)$ be a bts, $A \subseteq X$. Then, $\left.\tau_{12}\right|_{A}=\tau_{12}(A)$, where $\left.\tau_{12}\right|_{A}=\left\{A \cap U: U \in \tau_{12}\right\}$.

Theorem 2.3. [14] Let $\left(X, \tau_{1}, \tau_{2}\right)$ be a bts. Suppose that $B \subseteq A \subseteq X, B$ is a gp-closed set relative to $A$ and $A$ is a gp-closed set of $X$. Then, $B$ is a gp-closed set relative to $X$.

Corollary 2.2. [14] If $A$ is a gp-closed set and $F$ is P-closed set, then $A \cap F$ is a gp-closed set.

Theorem 2.4. [14] Let $\left(X, \tau_{1}, \tau_{2}\right)$ be a bts and $A \subseteq X$. If $A$ is a gp closed set and $A \subseteq B \subseteq \operatorname{cl}_{12}(A)$. Then, Bis a gp-closed set.

Theorem 2.5. [14] Let $\left(X, \tau_{1}, \tau_{2}\right)$ be a bts and $A \subseteq Y \subseteq X$. Suppose that $A$ is gp-closed in $X$. Then, $A$ is gp-closed relative to $Y$. 
Theorem 2.6. [14] Let $\left(X, \tau_{1}, \tau_{2}\right)$ be a bts, $\tau_{12}$ be supra topology on $X$ induced by $\tau_{1}, \tau_{2}$. Then, $\tau_{12}=\tau_{12}^{c}$ if and only if every subset of $X$ is a gp- closed set.

Definition 2.9. [14] A set $A$ is called a generalized pairwise open (briefly, gp-open) set if $A^{c}$ is a gp-closed set.

Theorem 2.7. [14] Let $\left(X, \tau_{1}, \tau_{2}\right)$ be a bts. Then, $A$ set $A$ is a gp-open set if and only if $F \subseteq$ int $t_{12}(A)$ whenever $F$ is a P-closed set and $F \subseteq A$.

Definition 2.10. [7] Let $\left(X, \tau_{1}, \tau_{2}\right)$ be a bts and $A \subseteq B \subseteq X$. Then, $A$ and $B$ are $P^{*}-\operatorname{separated}_{\text {in } X}$ if $A \cap c l_{12}(B)=\phi$ and $c l_{12}(A) \cap B=\phi$.

Not that if $A$ and $B$ are $P^{*}$-separated and $C \subseteq A, D \subseteq B$, then $C$ and $D$ are $P^{*}$ - separated.

Theorem 2.8. [14] Let $\left(X, \tau_{1}, \tau_{2}\right)$ be a bts. If $A$ and $B$ are $P^{*}$-separated and gp-open sets, then $A \cup B$ is a gp-open set.

Corollary 2.3. [14] Let $\left(X, \tau_{1}, \tau_{2}\right)$ be a bts and let $A$ and $B$ be two gp-closed sets and suppose that $A^{c}, B^{c}$ are $P^{*}-$ separated. Then, $A \cap B$ is a gp-closed set.

Theorem 2.9. [14] Let $\left(X, \tau_{1}, \tau_{2}\right)$ be a bts. Then, a set $A$ is gp-open if and only if $O=X$ whenever $O$ is a $P$-open and int $12(A) \cup A^{c} \subseteq O$.

Theorem 2.10. [14] Let $\left(X, \tau_{1}, \tau_{2}\right)$ be a bts and $A, B \in P(X)$. If int $\operatorname{in}_{12}(A) \subseteq B \subseteq A$ and $A$ is a gp-open set, then $B$ is gp-open set.

Theorem 2.11. [14] Let $\left(X, \tau_{1}, \tau_{2}\right)$ be a bts. Then, a set $A$ is a gp-closed if and only if $l_{12}(A) \backslash A$ is gp-open.

Definition 2.11. [14] Let $\left(X, \tau_{1}, \tau_{2}\right)$ be a bts. A space $\left(X, \tau_{1}, \tau_{2}\right)$ is said to be a pairwise symmetric (briefly, $P^{*}$-symmetric) if for all $x$ and $y$ in $X$, then $\left[x \in \operatorname{cl}_{12}\{y\} \Longrightarrow y \in \operatorname{cl}_{12}\{x\}\right]$.

Theorem 2.12. [14] A space $\left(X, \tau_{1}, \tau_{2}\right)$ is a $P^{*}$-symmetric if and only if $\{x\}$ is a gp- closed $\forall x \in X$.

Theorem 2.13. [14] Let $\left(X, \tau_{1}, \tau_{2}\right)$ and $\left(Y, \gamma_{1}, \gamma_{2}\right)$ be two bitopological spaces and $A$ be gp-closed set in $\left(X, \tau_{1}, \tau_{2}\right)$. ( $\left.X, \tau_{1}, \tau_{2}\right)$. Suppose that $f: X \longrightarrow Y$ is $P^{*}$-cts and $f$ is $P^{*}$-closed function, then $f(A)$ is a gp-closed set.

Remark 2.2. [14] If $f$ is $P^{*}$ - continuous and $P^{*}$-closed function and $A$ is gp-open set, then $f(A)$ is not necessary to be a gp-open set.

Theorem 2.14. [14] If $f:\left(X, \tau_{1}, \tau_{2}\right) \longrightarrow\left(Y, v_{1}, v_{2}\right)$ is $P^{*}$-cts and $P^{*}$-closed function, $B$ is a gp-closed (gp-open) subset of $Y$, then $f^{-1}(B)$ is gp-closed (gp-open) set in $X$, respectively.

\section{Generalized locally pairwise closed [resp., closed star, closed star star] sets.}

In this section we defined the concepts of locally pairwise closed sets, generalized locally pairwise closed sets, generalized locally pairwise closed star sets and generalized locally pairwise closed star star sets. Also we study some of their properties and find some relations between them.

Definition 3.1. Let $\left(X, \tau_{1}, \tau_{2}\right)$ be a bitopological space and $\tau_{12}=\left\{U \cup V: U \in \tau_{1}, V \in \tau_{2}\right\}$. A set $S$ is called locally P-closed set if $S=G \cap F$ where $G$ is $P$-open set and $F$ is $P$-closed set relative to $\tau_{12}$.

Remark 3.1. The following are well known:

1. A subset $S$ of space $\left(X, \tau_{12}\right)$ is locally P-closed set if and only if its complement $X \backslash S$ is the union of a P-open set and P-closed set.

2. Every P-open (resp., P-closed) set is locally P-closed sets.

3. The complement of locally P-closed set need not be locally P-closed set which shown by the following example.

Example 3.1. Let $X=\{1,2,3,4\}, \tau_{1}=\{X, \phi,\{4\}\}, \tau_{2}=\{X, \phi,\{1,2,4\}\}, \tau_{12}=\{X, \phi,\{4\},\{1,2,4\}\}, \tau_{12}^{c}=\{X, \phi,\{3\},\{1,2,3\}\}$. Then, $\{1,2\}$ is locally P-closed set that is to say $\{1,2\}=\{1,2,3\} \cap\{1,2,4\}$ but $\{1,2\}^{c}=\{3,4\}$ is not locally P-closed.

Definition 3.2. Let $\left(X, \tau_{1}, \tau_{2}\right)$ be a bitopological space and $\tau_{12}$ is the supra topology generated by $\tau_{1}$ and $\tau_{2}$. A subset $S$ in $\left(X, \tau_{12}\right)$ is called generalized locally pairwise closed set (briefly, GLPC set) if $S=G \cap F$ where $G$ is gp-open set and $F$ is gp-closed set.

Remark 3.2. Every gp-closed set (resp., gp-open set) is GLPC set.

The collection of all (generalized) locally pairwise closed sets of $\left(X, \tau_{1}, \tau_{2}\right)$ denoted by $G L P C$ [ resp., $\left.L P C\right]$.

Definition 3.3. Let $\left(X, \tau_{1}, \tau_{2}\right)$ be a bitopological space. For a subset $S$ of $X, S$ is called generalized locally pairwise closed star set (GLPC*) if there exist a gp-open set $G$ and $P$-closed set $F$ such that $S=G \cap F .\left[S \in G L P C^{*}\left(X, \tau_{12}\right)\right]$. 
Definition 3.4. Let $\left(X, \tau_{1}, \tau_{2}\right)$ be a bitopological space. For a subset $S$ of $X, S$ is called generalized locally pairwise closed star star set (GLPC $\left.{ }^{* *}\right)$ if there exist a P-open set $G$ and gp-closed set $F$ such that $S=G \cap F .\left[S \in \operatorname{GLPC}^{* *}\left(X, \tau_{12}\right)\right]$.

Proposition 3.1. Let $S$ be a set in $\left(X, \tau_{1}, \tau_{2}\right)$.

1. If $S \in L P C\left(X, \tau_{12}\right)$, then $S \in G L P C^{*}\left(X, \tau_{12}\right)$ and $S \in G L P C^{* *}\left(X, \tau_{12}\right)$. In other words, $L P C\left(X, \tau_{1}, \tau_{2}\right) \subseteq G L P C^{*}\left(X, \tau_{1}, \tau_{2}\right) \cap$ $G L P C^{* *}\left(X, \tau_{1}, \tau_{2}\right)$.

2. If $S \in G L P C^{*}\left(X, \tau_{12}\right)$ or $S \in G L P C^{* *}\left(X, \tau_{12}\right)$, then $S$ is generalized locally pairwise closed set. In other words, GLPC ${ }^{*}\left(X, \tau_{12}\right) \cup$ $G L P C^{* *}\left(X, \tau_{12}\right) \subseteq G L P C\left(X, \tau_{12}\right)$.

Proof. Let $\left(X, \tau_{1}, \tau_{2}\right)$ be a bitopological space. Then, $\left(X, \tau_{12}\right)$ is a supra topological space generated by $\tau_{1}$ and $\tau_{2}$.

1. Suppose that $S$ is locally P-closed set. Then $\exists$ P-open set $G$ and P-closed set $F$ such that, $S=G \cap F$. But, $G$ is P-open set and therefore it is $g p$-open set, $F$ is $\mathrm{P}$-closed set, it follows that $S \in G L P C^{*}\left(X, \tau_{12}\right)$. Similarly, the set $F$ is P-closed set implies, $F$ is $g p$-closed set. So, $S \in \operatorname{GLPC}^{* *}\left(X, \tau_{12}\right)$.

2. Let $S \in G L P C^{*}\left(X, \tau_{12}\right)$. Then, there exist $g p$-open $G$ and P-closed set $F$ such that $S=G \cap F$. But, every P-closed set is $g p$-closed set. Then, $S$ is $G L P C$ set.

Let $S \in G L P C^{* *}\left(X, \tau_{12}\right)$. Then, there exist P-open $G$ and $g p$-closed set $F$ such that $S=G \cap F$. But, every P-open set is $g p$-open set. Hence, $S$ is a $G L P C$ set.

Example 3.2. Let $X=\{a, b, c\}, \tau_{1}=\{X, \phi\}$ and $\tau_{2}=\{X, \phi,\{a\}\}$. Then, $\tau_{12}=\{X, \phi,\{a\}\}$. We get LPC $\left(X, \tau_{12}\right)=\{X, \phi,\{a\},\{b, c\}\}$ and $G L P C^{*}\left(X, \tau_{12}\right)=\operatorname{GLPC} C^{* *}\left(X, \tau_{12}\right)=\operatorname{GLPC}\left(X, \tau_{12}\right)=P(X)$.

Example 3.3. Let $X=\{a, b, c\}, \tau_{1}=\{X, \phi,\{a\}\}$ and $\tau_{2}=\{X, \phi,\{c\}\}$. Then, $\tau_{12}=\{X, \phi,\{a\},\{c\},\{a, c\}\}$. We get, LPC $\left(X, \tau_{12}\right)=$ $G L P C^{*}\left(X, \tau_{12}\right)=G L P C^{* *}\left(X, \tau_{12}\right)=G L P C\left(X, \tau_{12}\right)=P(X)$.

Theorem 3.1. Let $\left(X, \tau_{1}, \tau_{2}\right)$ be a bitopological space and $\left(X, \tau_{12}\right)$ is the supra topological space generated by $\tau_{1}$ and $\tau_{2}$. Then, for a subset $S$ in $\left(X, \tau_{12}\right)$ the following are equivalent:

1. $S \in L P C\left(X, \tau_{12}\right)$.

2. $S=G \cap \operatorname{cl}_{12}(S)$ for some $P$-open set $G$.

3. $\mathrm{cl}_{12}(S) \backslash S$ is $P$-closed set.

4. $S \cup\left(X \backslash \operatorname{cl}_{12}(S)\right)$ is $P$-open set.

5. $S \subseteq \operatorname{int}_{12}\left(S \cup X \backslash c l_{12}(S)\right)$.

Proof. (1) $\Longrightarrow(2)$. Let $S \in L P C\left(X, \tau_{12}\right)$. Then, $\exists P$-open set $G$ and P-closed set $F$ such that $S=G \cap F$. Since, $S \subseteq G$ and $S \subseteq F$ and $F$ is P-closed set which implies that $c_{12}(S) \subseteq F$. Then, $S \subseteq G \cap c l_{12}(S)$. Conversely, $S=G \cap F \supseteq G \cap c l_{12}(S)$. Hence, $S=G \cap c l_{12}(S)$.

$(2) \Longrightarrow(1)$. Since $G$ is $P$-open set and $c l_{12}(S)$ is P-closed set, then $G \cap c l_{12}(S) \in L P C\left(X, \tau_{12}\right)$ by Definition 3.1 .

$(2) \Longrightarrow(3)$. Let $S=P \cap c l_{12}(S)$ and $P$ be a $P$-open set. Then, $c l_{12}(S) \backslash S=c l_{12}(S) \cap\left[P^{c} \cup\left(c l_{12}(S)\right)^{c}\right]=c l_{12}(S) \cap P^{c} \cup \phi=c l_{12}(S) \cap P^{c}$. We have $c l_{12}(S)$ is P-closed set and $P^{c}$ is $P$-closed set then, $c l_{12}(S) \cap P^{c}$ is $P$-closed set. Hence, $c l_{12}(S) \backslash S$ is a $P$-closed set.

$(3) \Longrightarrow(2)$. We want to find a set $P$ which is $P$-open set such that $S=P \cap c l_{12}(S)$. Take $P=\left[c l_{12}(S) \backslash S\right]^{c}$ which is $P$ - open set and $S=\left[\operatorname{cl}_{12}(S) \backslash S\right]^{c} \cap \operatorname{cl}_{12}(S)$.

$(3) \Longrightarrow(4)$. Let $c l_{12}(S) \backslash S$ be a $P$-closed set. Then, $\left(c l_{12}(S) \backslash S\right)^{C}=\left[c l_{12}(S)\right]^{c} \cup S$ is a $P$ - open set. Hence, $X \backslash c l_{12}(S) \cup S$ is a $P-$ open set.

$(4) \Longrightarrow(3)$. Let $S \cup X \backslash c l_{12}(S)$ be a $P$-open set. Then, $\left[S \cup X \backslash c l_{12}(S)\right]^{c}=S^{c} \cap c l_{12}(S)=c l_{12}(S) \backslash S$ is a $P$ - closed set.

$(4) \Longrightarrow(5)$. Let $S \cup\left(X \backslash c l_{12}(S)\right)$ be a $P$-open set. Then, $S \subseteq S \cup\left(X \backslash \operatorname{cl}_{12}(S)\right)$. But, int $_{12}\left(S \cup\left(X \backslash c l_{12}(S)\right)=S \cup\left(X \backslash c l_{12}(S)\right.\right.$. Hence, $S \subseteq \operatorname{int}_{12}\left(S \cup X \backslash \operatorname{cl}_{12}(S)\right)$.

$(5) \Longrightarrow(4)$. Let $S \subseteq \operatorname{int}_{12}\left(S \cup X \backslash c l_{12}(S)\right)$. Then, $S \cup\left[X \backslash c l_{12}(S)\right] \subseteq \operatorname{int}_{12}\left(S \cup X \backslash c l_{12}(S)\right) \cup\left[X \backslash c l_{12}(S)\right]=\operatorname{int}_{12}\left(S \cup X \backslash c l_{12}(S) \cup i n t_{12}\left[X \backslash c l_{12}(S)\right]\right.$ $\subseteq \operatorname{int}_{12}\left(S \cup X \backslash \operatorname{cl}_{12}(S) \cup\left[X \backslash \operatorname{cl}_{12}(S)\right]\right)=\operatorname{int}_{12}\left(S \cup X \backslash \operatorname{cl}_{12}(S)\right)$. Then, $\left(S \cup X \backslash l_{12}(S)\right) \subseteq \operatorname{int}_{12}\left(S \cup X \backslash c l_{12}(S)\right)$. Hence, $S \cup X \backslash c l_{12}(S)$ is a P-open set.

Theorem 3.2. Let $\left(X, \tau_{1}, \tau_{2}\right)$ be a bitopological space and $\left(X, \tau_{12}\right)$ is the supra topological space generated by $\tau_{1}$ and $\tau_{2}$. Then, for a subset $S$ of $\left(X, \tau_{12}\right)$ the following are equivalent:

1. $S \in G L P C^{*}\left(X, \tau_{12}\right)$. 
2. $S=P \cap \operatorname{cl}_{12}(S)$ for some gp-open set $P$.

3. $\operatorname{cl}_{12}(S) \backslash S$ is gp-closed set.

4. $S \cup\left(X \backslash l_{12}(S)\right)$ is gp-open set.

Proof. (1) $\Longrightarrow(2)$. Let $S \in G L P C^{*}\left(X, \tau_{12}\right)$. Then $\exists g p$-open set $P$ and P-closed set $F$ such that $S=P \cap F$. Since, $S \subseteq P$ and $S \subseteq F$ and $F$ is P-closed set which implies that $c_{12}(S) \subseteq F$. Then, $S \subseteq P \cap c_{12}(S)$. Conversely, $S=P \cap F \supseteq P \cap c_{12}(S)$. Hence, $S=P \cap c l_{12}(S)$.

$(2) \Longrightarrow(1)$. Since $P$ is a $g p$-open set and $c l_{12}(S)$ is a P-closed set, then, $P \cap c l_{12}(S) \in G L P C^{*}\left(X, \tau_{12}\right)$ by Definition 3.3 .

$(2) \Longrightarrow(3)$. Let $S=P \cap c l_{12}(S)$ where $P$ is a $g p$-open set. Then, $c l_{12}(S) \backslash S=c l_{12}(S) \cap\left[P^{c} \cup\left(c l_{12}(S)\right)^{c}\right]=c l_{12}(S) \cap P^{c} \cup \phi=c l_{12}(S) \cap P^{c}$. We have $c l_{12}(S)$ is P-closed set and $P^{c}$ is $g p$-closed set then, by using Corollary 2.2, we get $c l_{12}(S) \cap P^{c}$ is a $g p$-closed set. Hence, $c l_{12}(S) \backslash S$ is a gp-closed set.

$(3) \Longrightarrow(2)$. We want to find a set $P$ which is $g p$-open set such that $S=P \cap c_{12}(S)$. Take $P=\left[c l_{12}(S) \backslash S\right]^{c}$ which is $g p$ - open set and $S=\left[c l_{12}(S) \backslash S\right]^{c} \cap c_{12}(S)$. set.

$(3) \Longrightarrow(4)$. Let $c l_{12}(S) \backslash S$ be a $g p$-closed set. Then, $\left(c l_{12}(S) \backslash S\right)^{C}=\left[c l_{12}(S)\right]^{c} \cup S$ is a $g p$ - open set. Hence, $X \backslash c l_{12}(S) \cup S$ is a $g p-$ open

$(4) \Longrightarrow(3)$. Let $S \cup X \backslash c l_{12}(S)$ be a $g p$-open set. Then, $\left[S \cup X \backslash c l_{12}(S)\right]^{c}=S^{c} \cap c l_{12}(S)=c l_{12}(S) \backslash S$ which is $g p-$ closed set.

Remark 3.3. In Example 3.2, if we take $S=\{a, b\}$, then $S \in G L P C^{*}\left(X, \tau_{12}\right)$. But, int $t_{12}\left(S \cup\left(X \backslash c l_{12}(S)\right)\right)=$ int $_{12}\{a, b\}=\{a\} \nsupseteq S(b y$ Theorem 3.2) .

Theorem 3.3. Let $\left(X, \tau_{1}, \tau_{2}\right)$ be a bitopological space and $\left(X, \tau_{12}\right)$ is the supra topological space generated by $\tau_{1}$ and $\tau_{2}$. Then, for a subset $S$ in $\left(X, \tau_{12}\right)$. If $S \in \operatorname{GLPC}^{* *}\left(X, \tau_{12}\right)$, then $P \cap i_{12} t_{12}(S) \subseteq S$ for some gp-closed set $P$.

Proof. Let $S \in G L P C^{* *}\left(X, \tau_{12}\right)$. Then $\exists$ gp-closed set $P$ and $P$-open set $G$ such that $S=P \cap G$. Since, $S \subseteq P$, then int $12(S) \subseteq P$, which implies that $P \cap \operatorname{int}_{12}(S) \cap S \subseteq S \cap P=S$. Hence, $P \cap \operatorname{int}_{12}(S) \subseteq S$.

Definition 3.5. Let $\left(X, \tau_{1}, \tau_{2}\right)$ be a bitopological space and $\left(X, \tau_{12}\right)$ is the supra topological space generated by $\tau_{1}$ and $\tau_{2}$. Then, a set $A$ is pairwise dense $\left(P-\right.$ dense) in $X$ if $\operatorname{cl}_{12}(A)=X$.

Definition 3.6. Let $\left(X, \tau_{1}, \tau_{2}\right)$ be a bitopological space and $\left(X, \tau_{12}\right)$ is the supra topological space generated by $\tau_{1}$ and $\tau_{2}$. Then, a space $X$ is called pairwise-submaximal [ briefly P-submaximal] if every P-dense subset is P-open set.

Definition 3.7. Let $\left(X, \tau_{1}, \tau_{2}\right)$ be a bitopological space and $\left(X, \tau_{12}\right)$ is the supra topological space generated by $\tau_{1}$ and $\tau_{2}$. A space $X$ is called generalized pairwise-submaximal if every $P$-dense subset is gp-open set.

Corollary 3.1. Let $\left(X, \tau_{1}, \tau_{2}\right)$ be a bitopological space and $\left(X, \tau_{12}\right)$ is the supra topological space generated by $\tau_{1}$ and $\tau_{2}$. Then, $P(X)=$ $\operatorname{LPC}\left(X, \tau_{12}\right)$ if and only if the space $X$ is P-submaximal.

Proof. Necessity: Let $S$ be a P-dense subset of $\left(X, \tau_{12}\right)$. Then, $c l_{12}(S)=X$ and by Theorem3.1 (4) we get, $S=S \cup\left(X \backslash c l_{12}(S)\right)$. So, $S \in \operatorname{LPC}\left(X, \tau_{12}\right)$ then, $S$ is $P$-open set. Hence, $X$ is $P$-submaximal.

Sufficiency: Let $S \in P(X)$ and take $U=S \cup\left(X \backslash c l_{12}(S)\right)$. Then, $c l_{12}(U)=c l_{12}(S) \cup c l_{12}\left[c l_{12}(S)\right]^{c}$. So, $c l_{12}(U)=X$ then we get, $U$ is $P$ - open set. But, $S=U \cap c l_{12}(S)$ and $c l_{12}(S)$ is P-closed set. This implies that $S \in L P C\left(X, \tau_{12}\right)$. Therefore, $P(X) \subseteq L P C\left(X, \tau_{12}\right)$ but in general we have, $\operatorname{LPC}\left(X, \tau_{12}\right) \subseteq P(X)$. Hence, $\operatorname{LPC}\left(X, \tau_{12}\right)=P(X)$.

Corollary 3.2. Let $\left(X, \tau_{1}, \tau_{2}\right)$ be a bitopological space and $\left(X, \tau_{12}\right)$ is the supra topological space generated by $\tau_{1}$ and $\tau_{2}$. Then, $P(X)=$ $\operatorname{GLPC}^{*}\left(X, \tau_{12}\right)$ if and only if the space $X$ is gp-submaximal.

Proof. Necessity: Let $S$ be a P-dense subset of $\left(X, \tau_{12}\right)$. Then, $c l_{12}(S)=X$ and by Theorem3.2 (4) we get, $S=S \cup\left(X \backslash c l_{12}(S)\right)$. So, $S \in G L P C^{*}\left(X, \tau_{12}\right)$ then, $S$ is $g p$-open set. Hence, $X$ is a $g p$-submaximal.

Sufficiency: Let $S \in P(X)$ and take $U=S \cup\left(X \backslash c l_{12}(S)\right)$. Then, $c l_{12}(U)=c l_{12}(S) \cup c l_{12}\left[c l_{12}(S)\right]^{c}$. So, $c l_{12}(U)=X$ then we get, $U$ is $g p$ - open set. But, $S=U \cap c l_{12}(S)$ and $\operatorname{cl}_{12}(S)$ is P-closed set. This implies that $S \in G L P C^{*}\left(X, \tau_{12}\right)$ therefore, $P(X) \subseteq G L P C^{*}\left(X, \tau_{12}\right)$ but in general we have, $\operatorname{GLPC}^{*}\left(X, \tau_{12}\right) \subseteq P(X)$. Hence, $\operatorname{GLPC} C^{*}\left(X, \tau_{12}\right)=P(X)$.

Remark 3.4. Let $\left(X, \tau_{1}, \tau_{2}\right)$ be a bitopological space and $\left(X, \tau_{12}\right)$ is the supra topological space generated by $\tau_{1}$ and $\tau_{2}$. If the space $X$ is $P$ submaximal, then it is gp-submaximal but the converse is not true. (See Example 3.2 which shows $P(X)=G L P C^{*}\left(X, \tau_{12}\right)$ but $L P C\left(X, \tau_{12}\right) \neq$ $P(X))$. 
Theorem 3.4. Let $\left(X, \tau_{1}, \tau_{2}\right)$ be a bitopological space and $\left(X, \tau_{12}\right)$ is the supra topological space generated by $\tau_{1}$ and $\tau_{2}$. Suppose $A$ and $B$ be subset of $X$.

1. If $A \in G L P C^{* *}\left(X, \tau_{12}\right)$ and $B$ is $P$-closed, then $A \cap B \in G L P C^{* *}\left(X, \tau_{12}\right)$.

2. If $A \in G L P C\left(X, \tau_{12}\right)$ and $B$ is $P$-closed, then, $A \cap B \in G L P C\left(X, \tau_{12}\right)$.

Proof. (1) Let $A \in \operatorname{GLPC}^{* *}\left(X, \tau_{12}\right)$. Then, $\exists \mathrm{P}$-open set $Q$ and $g p$ - closed set $P$ such that $A=P \cap Q$. Take $B \subseteq X$ which is $\mathrm{P}$-closed set this implies that $A \cap B=Q \cap P \cap B$. But, $P \cap B$ is $g p$ - closed set ( by Corollary 2.2 ). Hence, $A \cap B \in G L P C^{* *}\left(X, \tau_{12}\right)$.

(2) Let $A \in G L P C\left(X, \tau_{12}\right)$. Then, $\exists g p$ - open set $F$ and $g p$ - closed set $G$ such that $A=F \cap G$. Take $B \subseteq X$ which is P-closed set therefore, $B \cap G$ is $g p$ - closed set. Hence, $A \cap B \in G L P C\left(X, \tau_{12}\right)$.

Remark 3.5. In Theorem 3.4 we can note that:

(1) if $B$ is $P$-open set, then $A \cap B$ is not necessary belong to $G L P C^{* *}\left(X, \tau_{12}\right)$.

(2) if $B$ is P-open set, then $A \cap B$ is not necessary belong to $G L P C\left(X, \tau_{12}\right)$, (see Example 3.4).

Example 3.4. Let $X=\{1,2,3,4,5\}, \tau_{1}=\{X, \phi,\{1,2,3\}\}$ and $\tau_{2}=\{X, \phi,\{3,4,5\}\}$. Then, $\tau_{12}=\{X, \phi,\{1,2,3\},\{3,4,5\}\}, \tau_{12}^{c}=\{X, \phi\{4,5\},\{1,2\}\}$. Take $A=\{1,2,3\}, B=\{3,4,5\}$. So, $A \in G L P C^{* *}\left(X, \tau_{12}\right), B \in \tau_{12}$ but, $A \cap B=\{3\} \notin G L P C\left(X, \tau_{12}\right)$ and $A \cap B \notin G L P C^{* *}\left(X, \tau_{12}\right)$.

Theorem 3.5. Let $\left(X, \tau_{1}, \tau_{2}\right)$ be a bitopological space and $\left(X, \tau_{12}\right)$ is the supra topological space generated by $\tau_{1}$ and $\tau_{2}$. Suppose $A$ and $B$ are subsets of $X$ and $A \subseteq B$. If $B$ is gp-closed set in $\left(X, \tau_{12}\right)$ and $A \in G L P C^{* *}\left(B,\left.\tau_{12}\right|_{B}\right)$, then, $A \in G L P C^{* *}\left(X, \tau_{12}\right)$.

Proof. Let $B$ be a $g p$ - closed set in $X$ and $A \in G L P C^{* *}\left(B,\left.\tau_{12}\right|_{B}\right)$. Then, there exist P-open set $Q$ of $\left(B,\left.\tau_{12}\right|_{B}\right)$ and $g p$-closed set $M$ of $\left(B,\left.\tau_{12}\right|_{B}\right)$ such that, $A=Q \cap M$ but we have $Q=B \cap S$ for some $S \in \tau_{12}$ and $M$ is $g p$ - closed set in $\left.\tau_{12}\right|_{B}$, then $M$ is $g p$ - closed set in $\tau_{12}$ (Theorem 2.3). So, $A=(B \cap S) \cap M=S \cap M$ since, $A \subseteq B, M \subseteq B$. Hence, $A \in G L P C^{* *}\left(X, \tau_{12}\right)$.

Definition 3.8. Let $\left(X, \tau_{1}, \tau_{2}\right)$ be a bitopological space and $\left(X, \tau_{12}\right)$ is the supra topological space generated by $\tau_{1}$ and $\tau_{2}$. Then,

1. A set $S$ is called locally pairwise open set (briefly, $L P O$ - set) if $S^{c} \in L P C\left(X, \tau_{12}\right)$. The family of all locally pairwise open set denoted by $L P O\left(X, \tau_{12}\right)$.

2. A set $S$ is called generalized locally pairwise open set (briefly, GLPO- set) if $S^{c} \in G L P C\left(X, \tau_{12}\right)$. The family of all generalized locally pairwise open set denoted by $G L P O\left(X, \tau_{12}\right)$.

3. A set $S$ is called generalized locally pairwise open star set (briefly, GLPO*- set) if $S^{c} \in G L P C^{*}\left(X, \tau_{12}\right)$. The family of all generalized locally pairwise open star set denoted by $\operatorname{GLPO}^{*}\left(X, \tau_{12}\right)$.

4. A set $S$ is called generalized locally pairwise open star star set (briefly, GLPO** set) if $S^{c} \in G L P C^{* *}\left(X, \tau_{12}\right)$. The family of all generalized locally pairwise open star stare set denoted by $\operatorname{GLPO}^{* *}\left(X, \tau_{12}\right)$.

Proposition 3.2. Let $\left(X, \tau_{1}, \tau_{2}\right)$ be a bitopological space and $\left(X, \tau_{12}\right)$ is the supra topological space generated by $\tau_{1}$ and $\tau_{2}$. Then, $S \in L P O\left(X, \tau_{12}\right)$ implies that $\exists P$-open set $G$ and $P$-closed set $F$ such that $S=G \cup F$.

Proof. It is follows from definition of $\operatorname{LPC}\left(X, \tau_{12}\right)$.

Proposition 3.3. Let $\left(X, \tau_{1}, \tau_{2}\right)$ be a bitopological space and $\left(X, \tau_{12}\right)$ is the supra topological space generated by $\tau_{1}$ and $\tau_{2}$. Then, $S \in$ $G L P O\left(X, \tau_{12}\right)$ implies that $\exists$ gp-open set $G$ and gp-closed set $F$ such that $S=G \cup F$.

Proof. It is follows from definition of $\operatorname{GLPC}\left(X, \tau_{12}\right)$.

Proposition 3.4. Let $\left(X, \tau_{1}, \tau_{2}\right)$ be a bitopological space and $\left(X, \tau_{12}\right)$ is the supra topological space generated by $\tau_{1}$ and $\tau_{2}$. Then, $S \in$ $G L P O^{*}\left(X, \tau_{12}\right)$ implies that $\exists P$-open set $G$ and gp-closed set $F$ such that $S=G \cup F$.

Proof. It is follows from definition of $\operatorname{GLPC}^{*}\left(X, \tau_{12}\right)$

Proposition 3.5. Let $\left(X, \tau_{1}, \tau_{2}\right)$ be a bitopological space and $\left(X, \tau_{12}\right)$ is the supra topological space generated by $\tau_{1}$ and $\tau_{2}$. Then, $S \in$ $G L P O^{* *}\left(X, \tau_{12}\right)$ implies that $\exists g p$-open set $G$ and $P$-closed set $F$ such that $S=G \cup F$.

Proof. It is straightforward from definition of $G L P C^{* *}\left(X, \tau_{12}\right)$.

Proposition 3.6. Let $S$ be a subset in $\left(X, \tau_{1}, \tau_{2}\right)$.

1. If $S$ is locally pairwise open set, then $S \in G L P O^{*}\left(X, \tau_{12}\right)$ and $S \in G L P O^{* *}\left(X, \tau_{12}\right)$. In other words, $L P O\left(X, \tau_{1}, \tau_{2}\right) \subseteq G L P O^{*}\left(X, \tau_{1}, \tau_{2}\right) \cap$ $\operatorname{GLPO}^{* *}\left(X, \tau_{1}, \tau_{2}\right)$.

2. If $S \in G L P O^{*}\left(X, \tau_{12}\right)$ or $S \in G L P O^{* *}\left(X, \tau_{12}\right)$, then $S$ is generalized locally pairwise open set. In other words, $G L P O^{*}\left(X, \tau_{12}\right) \cup$ $\operatorname{GLPO}^{* *}\left(X, \tau_{12}\right) \subseteq G L P O\left(X, \tau_{12}\right)$ 
Proof. (1). Let $S \in L P O\left(X, \tau_{12}\right)$. Then, $S^{c} \in L P C\left(X, \tau_{12}\right)$. By Proposition $3.1(1), S^{c} \in G L P C^{*}\left(X, \tau_{12}\right) \cap G L P C^{* *}\left(X, \tau_{12}\right)$. Hence, $S \in G L P O^{*}\left(X, \tau_{12}\right) \cap G L P O^{* *}\left(X, \tau_{12}\right)$.

(2). Let $S \in G L P O^{*}\left(X, \tau_{12}\right)$. Then, $S^{c} \in G L P C^{*}\left(X, \tau_{12}\right)$. By Proposition $3.1(2), S^{c} \in G L P C\left(X, \tau_{12}\right)$, then $S \in G L P O\left(X, \tau_{12}\right)$. Let $S \in G L P O^{* *}\left(X, \tau_{12}\right)$. Then, $S^{c} \in G L P C^{* *}\left(X, \tau_{12}\right)$. By Proposition $3.1(2), S^{c} \in G L P C\left(X, \tau_{12}\right)$, then $S \in G L P O\left(X, \tau_{12}\right)$. Note that the family of $L P O\left(X, \tau_{12}\right)$ may be not a topology and may be not supra topology on $X$ as shown in the following Example 3.5.

Example 3.5. Let $X=\{a, b, c, d\}, \tau_{1}=\{X, \phi,\{a, b\}\}, \tau_{2}=\{X, \phi,\{b, c\}\}$. Then, $\tau_{12}=\{X, \phi,\{a, b\},\{b, c\},\{a, b, c\}\}, \tau_{12}^{c}=\{X, \phi\{c, d\},\{a, d\},\{d\}\}$ and $L P O\left(X, \tau_{12}\right)=\{X, \phi,\{a, b\},\{b, c\},\{a, b, c\},\{c, d\},\{a, d\},\{d\},\{a, b, d\},\{b, c, d\}\}$. We have, $\{a, b\} \cap\{a, d\}=\{a\} \notin L P O\left(X, \tau_{12}\right)$ and $\{c, d\} \cup$ $\{a, d\}=\{a, c, d\} \notin L P O\left(X, \tau_{12}\right)$. Therefore, LPO $\left(X, \tau_{12}\right)$ neither topology not supra topology on $X$.

Theorem 3.6. Let $\left(X, \tau_{1}, \tau_{2}\right)$ be a bitopological space and $\left(X, \tau_{12}\right)$ is the supra topological space generated by $\tau_{1}$ and $\tau_{2}$. Then, for a subset $S$ in $\left(X, \tau_{12}\right)$ the following are equivalent:

1. $S \in L P O\left(X, \tau_{12}\right)$.

2. $S=F \cup \operatorname{int}_{12}(S)$ for some P-closed set $F$.

3. $S^{c} \cup \operatorname{int}_{12}(S)$ is P-open set.

4. $S \backslash \operatorname{int}_{12}(S)$ is P-closed set.

5. $S \supseteq \operatorname{cl}_{12}\left(S \backslash \operatorname{int}_{12}(S)\right)$.

Proof. $\quad(1) \Longrightarrow(2)$. Let $S \in L P O^{*}\left(X, \tau_{12}\right)$. Then $S^{c} \in L P C\left(X, \tau_{12}\right)$. By Theorem 3.1, $S^{c}=G \cap c l_{12}(X \backslash S)$, G is P-open set. Then, $S=G^{c} \cup\left(c l_{12}(X \backslash S)\right)^{c}$. Hence, $S=G^{c} \cup \operatorname{int}_{12}(S)$.

$(2) \Longrightarrow(1)$. Let $S=F \cup \operatorname{int}_{12}(S), F$ is P-closed set and we have $\operatorname{int}_{12}(S)$ is P-open set. Hence, $S \in L P O\left(X, \tau_{12}\right)$.

$(2) \Longrightarrow(3)$. Let $S=F \cup$ int $_{12}(S)$ for some P-closed set $F$. Then, $S^{c} \cup i n t_{12}(S)=\left(F \cup i_{12}(S)\right)^{c} \cup i_{12} t_{12}(S)=\left(F^{c} \cap\left(\text { int }_{12} S\right)^{c}\right) \cup i n t_{12}(S)$ $\left.=\left(F^{c} \cup i n t_{12} S\right) \cap\left(\left(i n t_{12} S\right)^{c}\right) \cup i n t_{12} S\right)=\left(F^{c} \cup i n t_{12} S\right) \cap X=F^{c} \cup i n t_{12}(S)$. Since, $F^{c}$ is P-open and int $12(S)$ is P-open, then $S^{c} \cup i n t_{12} S$ is a P-open set.

$(3) \Longrightarrow(2)$. Let $S^{c} \cup \operatorname{int}_{12}(S)$ be P-open set. Then, $\left(S^{c} \cup i n t_{12}(S)\right)^{c}=S \cap\left(i n t_{12} S\right)^{c}$ is P-closed set. Take $F=S \cap\left(i n t_{12} S\right)^{c}$. Now, $F \cup$ int $_{12} S=S \cap\left(\text { int }_{12} S\right)^{c} \cup \operatorname{int}_{12} S=\left(S \cup \operatorname{int}_{12}(S)\right) \cap\left(\text { int }_{12} S\right)^{c} \cup \operatorname{int}_{12} S=\left(S \cup\right.$ int $\left._{12}(S)\right)=S$. Hence, $S=F \cup$ int $_{12} S$.

$(3) \Longrightarrow(4)$. Let $S^{c} \cup i n t_{12} S$ be P-open set. Then, $\left(S^{c} \cup i n t_{12} S\right)^{c}$ is P-closed. Hence, $S \cap\left(\text { int }_{12}(S)\right)^{c}=S \backslash i n t_{12} S$ is a P-closed set.

$(4) \Longrightarrow(3)$. Let $S \backslash \operatorname{int}_{12} S$ be P-closed set. Then, $\left(S \cap\left(\text { int }_{12} S\right)^{c}\right)^{c}=S^{c} \cup i n t_{12} S$ is a P-open set.

$(4) \Longrightarrow(5)$. Let $S \backslash i n t_{12} S$ be P-closed set. Then, $S \supseteq S \backslash i n t_{12}$. But $c_{12}\left(S \backslash i n t_{12} S\right)=S \backslash i n t_{12} S$. This implies that $S \supseteq c l_{12}\left(S \backslash i n t_{12}(S)\right)$.

$(5) \Longrightarrow(4) . \quad$ Let $S \supseteq c l_{12}\left(S \backslash \operatorname{int}_{12}(S)\right) . \quad$ Then, $S \cap\left(\text { int }_{12} S\right)^{c} \supseteq \operatorname{cl}_{12}\left(S \backslash \operatorname{int}_{12} S\right) \cap\left(\text { int }_{12}(S)\right)^{c} \supseteq \operatorname{cl}_{12}\left(S \backslash\right.$ int $\left._{12} S\right) \cap c l_{12}\left(\text { int }_{12}(S)\right)^{c} \supseteq$ $c_{12}\left(\left(S \backslash\right.\right.$ int $\left.\left._{12} S\right) \cap\left(\text { int }_{12}(S)\right)^{c}\right)$ but, $S \cap\left(\text { int }_{12} S\right)^{c} \subseteq c_{12}\left(S \cap\left(\text { int }_{12} S\right)^{c}\right)$. Hence, $c l_{12}\left(S \cap\left(\text { int }_{12} S\right)^{c}\right)=S \cap\left(\text { int }_{12} S\right)^{c}$. Consequentially, $S \cap\left(\text { int }_{12} S\right)^{c}=$ $\left(S \backslash i n t_{12} S\right)$ is a P-closed. Hence, the result.

Theorem 3.7. Let $\left(X, \tau_{1}, \tau_{2}\right)$ be a bitopological space and $\left(X, \tau_{12}\right)$ is the supra topological space generated by $\tau_{1}$ and $\tau_{2}$. Then, for a subset $S$ in $\left(X, \tau_{12}\right)$ the following are equivalent:

1. $S \in G L P O^{*}\left(X, \tau_{12}\right)$.

2. $S=F \cup \operatorname{int}_{12}(S)$ for some gp-closed set $F$.

3. $S^{c} \cup \operatorname{int}_{12}(S)$ is gp-open set.

4. $S \backslash \operatorname{int}_{12}(S)$ is gp-closed set.

Proof. (1) $\Longrightarrow(2)$. Let $S \in G L P O^{*}\left(X, \tau_{12}\right)$. Then $S^{c} \in G L P C^{*}\left(X, \tau_{12}\right)$. By Theorem $3.2, S^{c}=P \cap c l_{12}(S)$, for some $g p$-open set $P$. Therefore, $S=P^{c} \cup\left(c l_{12}(X \backslash S)\right)^{c}$. Hence, $S=P^{c} \cup \operatorname{int}_{12}(S)$.

$(2) \Longrightarrow(1)$. Let $S=F \cup \operatorname{int}_{12}(S), F$ is P-closed set and we have $\operatorname{int}_{12}(S)$ is P-open set. Hence, $S \in L P O\left(X, \tau_{12}\right)$.

$(2) \Longrightarrow(3)$. Let $S=F \cup \operatorname{int}_{12}(S)$ for some $g p$-closed set $F$. Then, $S^{c} \cup \operatorname{int}_{12}(S)=\left(F \cup \operatorname{int}_{12}(S)\right)^{c} \cup$ int $_{12}(S)=\left(F^{c} \cap\left(\text { int }_{12} S\right)^{c}\right) \cup$ int $_{12}(S)$ $=\left(F^{c} \cup\right.$ int $\left._{12} S\right) \cap\left(\left(\left(\operatorname{int}_{12} S\right)^{c}\right) \cup i n t_{12} S\right)=\left(F^{c} \cup i n t_{12} S\right) \cap X=F^{c} \cup i n t_{12}(S)$. Since, $F^{c}$ is $g p$-open and int $t_{12}(S)$ is P-open. Now, $F$ is $g p-$ closed set and $\left(i n t_{12} S\right)^{c}$ is P-closed set. Then by Corollary $2.2, F \cap\left(i n t_{12} S\right)^{c}$ is $g p$-closed set and therefore $F^{c} \cup i n t_{12} S$ is $g p$-open set. Hence, $S^{c} \cup i n t_{12} S$ is a $g p$-open set. 
$(3) \Longrightarrow(2)$. Taking the complement of no(3). From(3) we have $\left(S^{c} \cup i n t_{12}(S)\right)^{c}=S \cap\left(\text { int }_{12} S\right)^{c}=F$ which is $g p$-closed set. Now, $F \cup \operatorname{int}_{12} S=\left(S \cap\left(\operatorname{int}_{12} S\right)^{c}\right) \cup \operatorname{int}_{12} S=\left(S \cup i n t_{12} S\right) \cap X=S \cup \operatorname{int}_{12}(S)$.

$(3) \Longrightarrow(4)$. Let $S \cup i n t_{12} S$ be $g p$-open set. Then, $\left(S^{c} \cup i n t_{12} S\right)^{c}$ is $g p$-closed. Hence, $S \cap\left(i n t_{12}(S)\right)^{c}=S \backslash i n t_{12} S$ is a $g p$-closed set.

$(4) \Longrightarrow(3)$.Let $S \backslash i n t_{12} S$ be $g p$-closed set. Then, $\left(S \cap\left(i n t_{12} S\right)^{c}\right)^{c}=S^{c} \cup i n t_{12} S$ is $g p$-open set. Hence, the result.

Theorem 3.8. Let $\left(X, \tau_{1}, \tau_{2}\right)$ be a bitopological space and $\left(X, \tau_{12}\right)$ be a supra topological space generated by $\tau_{1}$ and $\tau_{2}$. Suppose $A$ and $B$ be subsets of $X$.

1. If $A \in G L P O^{* *}\left(X, \tau_{12}\right)$ and $B$ is $P$-open, then $A \cup B \in G L P O^{* *}\left(X, \tau_{12}\right)$.

2. If $A \in G L P O\left(X, \tau_{12}\right)$ and $B$ is P-open, then $A \cup B \in G L P O\left(X, \tau_{12}\right)$.

Proof. (1). Let $A \in G_{L P O}^{* *}\left(X, \tau_{12}\right)$. Then, $\exists$ P-closed set $Q$ and $g p$ - open set $P$ such that $A=P \cup Q$. Take $B \subseteq X$ which is $\mathrm{P}$-open set this implies that $A \cup B=Q \cup P \cup B$. But, $P \cup B$ is $g p$-open set. Hence, $A \cup B \in \operatorname{GLPO}^{* *}\left(X, \tau_{12}\right)$.

(2). Let $A \in G L P O\left(X, \tau_{12}\right)$. Then, $\exists g p$ - open set $G$ and $g p$ - closed set $F$ such that $A=F \cup G$. Take $B \subseteq X$ which is P-open set, then $B \cup G$ is gp- open set. Hence, $A \cup B \in G L P O\left(X, \tau_{12}\right)$.

Remark 3.6. In Theorem 3.4 we can note that:

(1) if $B$ is $P$-closed set, then $A \cup B$ is not necessary belong to $G L P O^{* *}\left(X, \tau_{12}\right)$.

(2) if $B$ is $P$-closed set, then $A \cup B$ is not necessary belong to $G L P O\left(X, \tau_{12}\right)$. In Example 3.4 we have $A=\{4,5\} \in G L P O^{* *}$ and $B=\{1,2\} \in \tau_{12}^{c}$ but, $A \cup B=\{1,2,4,5\} \notin G L P O\left(X, \tau_{12}\right)$ and $A \cup B \notin G L P O^{* *}\left(X, \tau_{12}\right)$.

\section{Generalized locally pairwise closed-Functions and some of their properties}

Let $f: X \longrightarrow Y$ be a function between two bitoplogical spaces $\left(X, \tau_{1}, \tau_{2}\right)$ and $\left(Y, \nu_{1}, \nu_{2}\right)$. We use the notations in this section $L P C$ - continuity, $L P C$-irresoluteness and sub- $L P C$ - continuity. After that we define generalization of $L P C$-irresolute functions, $L P C$-continuous function and sub- $L P C$-continuous function and study some of their properties.

Definition 4.1. Let $f: X \longrightarrow Y$ be a function between two bitoplogical spaces $\left(X, \tau_{1}, \tau_{2}\right)$ and $\left(Y, \nu_{1}, \nu_{2}\right)$. Suppose $\left(X, \tau_{12}\right)$ and $\left(Y, \nu_{12}\right)$ are the supra topological spaces associated to $\left(X, \tau_{1}, \tau_{2}\right)$ and $\left(Y, \nu_{1}, \nu_{2}\right)$, respectively. Then, a function $f$ is called

1. $L P C$-irresolute if $f^{-1}(A) \in L P C\left(X, \tau_{12}\right) \forall A \in L P C\left(Y, \nu_{12}\right)$.

2. $L P C$ - continuous if $f^{-1}(G) \in L P C\left(X, \tau_{12}\right), \forall G \in \nu_{12}$.

3. Sub-LPC-continuous if there is a base $\beta$ for $\left(Y, \nu_{12}\right)$ such that $f^{-1}(V) \in L P C\left(X, \tau_{12}\right), \forall V \in \beta$.

Definition 4.2. Let $f:\left(X, \tau_{1}, \tau_{2}\right) \longrightarrow\left(Y, \nu_{1}, \nu_{2}\right)$ be a function. Suppose $\left(X, \tau_{12}\right)$ and $\left(Y, \nu_{12}\right)$ are the supra topological spaces associated to $\left(X, \tau_{1}, \tau_{2}\right)$ and $\left(Y, \nu_{1}, \nu_{2}\right)$, respectively. Then, a function $f$ is called GLPC-irresolute [resp., GLPC*-irresolute, GLPC ${ }^{* *}-$ irresolute] if $f^{-1}(V) \in G L P C\left(X, \tau_{12}\right)$ [resp., $\left.f^{-1}(V) \in G L P C^{*}\left(X, \tau_{12}\right), f^{-1}(V) \in G L P C^{* *}\left(X, \tau_{12}\right)\right], \forall V \in G L P C\left(Y, \nu_{12}\right)\left[r e s p ., \forall V \in G L P C^{*}\left(Y, \nu_{12}\right)\right.$, $\left.\forall V \in G L P C^{* *}\left(Y, \nu_{12}\right)\right]$.

Definition 4.3. Let $f:\left(X, \tau_{1}, \tau_{2}\right) \longrightarrow\left(Y, \nu_{1}, \nu_{2}\right)$ be a mapping. Suppose $\left(X, \tau_{12}\right)$ and $\left(Y, \nu_{12}\right)$ are the supra topological spaces associted to $\left(X, \tau_{1}, \tau_{2}\right)$ and $\left(Y, \nu_{1}, \nu_{2}\right)$, respectively. Then, a function $f$ is called $G L P C-$ continuous [ resp., GLPC* - continuous, GLPC ${ }^{* *}-$ continuous ] if $f^{-1}(V) \in G L P C\left(X, \tau_{12}\right)$ [resp., $\left.\left.f^{-1}(V) \in G L P C^{*}\left(X, \tau_{12}\right), f^{-1}(V) \in G L P C^{* *}\left(X, \tau_{12}\right)\right)\right] \forall V \in \nu_{12}$.

Theorem 4.1. Let $f:\left(X, \tau_{1}, \tau_{2}\right) \longrightarrow\left(Y, \nu_{1}, \nu_{2}\right)$ be a mapping. Suppose $\left(X, \tau_{12}\right)$ and $\left(Y, \nu_{12}\right)$ are the supra topological spaces associated to by $\left(X, \tau_{1}, \tau_{2}\right)$ and $\left(Y, \nu_{1}, \nu_{2}\right)$, respectively.

1. If $f$ is $L P C$-continuous, then it is $G L P C^{*}$-continuous and $G L P C^{* *}$-continuous.

2. If $f$ is $G L P C^{*}$-continuous or $G L P C^{* *}$-continuous, then it is $G L P C$-continuous.

3. If $f$ is $G L P C$-irresolute (resp. GLPC ${ }^{*}$-irresolute, GLPC ${ }^{* *}$-irresolute), then it is GLPC-continuous (resp. GLPC ${ }^{*}$-continuous, GLPC ${ }^{* *}$ continuous)

4. If $f$ is $P^{*}$-continuous function and $P^{*}-$ closed function, then $f$ is $G L P C$-irresolute function, $G L P C^{*}$-irresolute function and $G L P C^{* *}$ irresolute function.

Proof.

1. Suppose that $f$ is $L P C$ - continuous. Let $V \in \nu_{12}$. Then, $f^{-1}(V) \in L P C\left(X, \tau_{12}\right)$. By using Proposition 3.1 we get $f^{-1}(V) \in G L P C^{*}\left(X, \tau_{12}\right)$ and $f^{-1}(V) \in G L P C^{* *}\left(X, \tau_{12}\right)$. Hence, $f$ is a $G L P C^{*}$ - continuous and $G L P C^{* *}$ - continuous.

2. It is follows from Proposition 3.1. Since every P-open set is $g p$-open set and every P-closed set is $g p$ - closed set. 
3. Also can be done like no.(2)

4. Let $f$ be $P^{*}$-continuous and $P^{*}$ closed function. Suppose that $A \in G L P C^{*}\left(Y, \nu_{12}\right)$ we want to prove that $f^{-1}(A) \in G L P C^{*}\left(X, \tau_{12}\right)$. Then, $\exists$ P-closed set $F$ and $g p$ - open set $G$ such that $A=G \cap F$ by using Theorem 2.14 we get $f^{-1}(G)$ is $g p$-open set and $f^{-1}(F)$ is P-closed set this implies that, $f^{-1}(A)=f^{-1}(G \cap F)=f^{-1}(G) \cap f^{-1}(F)$. Hence, $f^{-1}(A) \in G L P C^{*}\left(X, \tau_{12}\right)$. Similarly, we can show that $f$ is $G L P C$ irresolute function and $G L P C^{* *}$ - irresolute function.

Remark 4.1. The converse of Theorem 4.1 need not be true in general as shown in the following examples.

Example 4.1. Let $X=Y=\{1,2,3\}, \tau_{1}=\{X, \phi\}, \tau_{2}=\{X, \phi,\{1\}\}, \nu_{1}=\{X, \phi\}$ and $\nu_{2}=P(Y)$. Then, $\tau_{12}=\{X, \phi,\{1\}\}, \nu_{12}=P(Y)$. Take $f: X \longrightarrow Y ; f(x)=x \forall x \in X$ which is the identity function. $G L P C\left(X, \tau_{12}\right)=G L P C^{*}\left(X, \tau_{12}\right)=G L P C^{* *}\left(X, \tau_{12}\right)=P(X)$. So, $L P C\left(X, \tau_{12}\right)=\{X, \phi,\{1\},\{2,3\}\} . G L P C\left(Y, \nu_{12}\right)=G L P C^{*}\left(Y, \nu_{12}\right)=G L P C^{* *}\left(Y, \nu_{12}\right)=L P C\left(Y, \nu_{12}\right)=P(Y)$. We have $f$ is not LPCcontinuous, but it is $G L P C^{*}$ - continuous, GLPC ${ }^{* *}$ - continuous and $G L P C^{*}$ - irresolute.

Example 4.2. Let $X=Y=\{1,2,3\}, \tau_{1}=\{X, \phi,\{1\}\}, \tau_{2}=\{X, \phi,\{1,2\}\}, \nu_{1}=\{X, \phi\}$ and $\nu_{2}=\{X, \phi,\{1\}\}$. Then, $\tau_{12}=\{X, \phi,\{1\},\{1,2\}\}$, $\nu_{12}=\{X, \phi,\{1\}\}$. Take $f: X \longrightarrow Y ; f(1)=f(3)=1, f(2)=2$. Hence, $G L P C\left(Y, \nu_{12}\right)=G L P C^{*}\left(X, \nu_{12}\right)=G L P C^{* *}\left(X, \nu_{12}\right)=P(X)$. Then, $f$ is not $G L P C^{*}-$ continuous but it is $G L P C-$ continuous and it is $G L P C^{* *}-$ continuous.

Example 4.3. Let $X=Y=\{1,2,3\}, \tau_{1}=\{X, \phi,\{1\}\}, \tau_{2}=\{X, \phi,\{1,2\}\}, \nu_{1}=\{X, \phi\}$ and $\nu_{2}=\{X, \phi,\{1\}\}$. Then, $\tau_{12}=\{X, \phi,\{1\},\{1,2\}\}$, $\nu_{12}=\{X, \phi,\{1\}\}$. Take $f: X \longrightarrow Y ; f(x)=x$ which is the identity function. Then, $\{1,3\} \in G L P C^{*}\left(y, \nu_{12}\right)$ but, $\{1,3\} \notin G L P C^{*}\left(X, \tau_{12}\right)$. Hence, $f$ is not $G L P C^{*}$ - irresolute but it is LPC-continuous.

On account of Theorem 4.1 and Examples $4.1,4.2$ and 4.3 we have the following corollary.

Corollary 4.1. Let $f:\left(X, \tau_{1}, \tau_{2}\right) \longrightarrow\left(Y, \nu_{1}, \nu_{2}\right)$ be a mapping. Then, we have the following diagram:

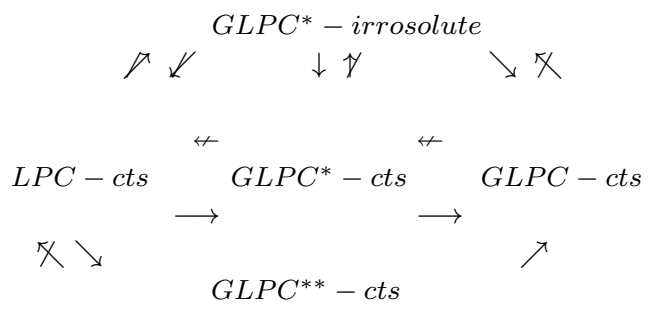

Theorem 4.2. If $f: X \longrightarrow Y$ is $G L P C^{* *}-$ continuous and $B$ is $P$-closed set in $\left(X, \tau_{12}\right)$, then the restriction of $f$ to $B$ say $\left.f\right|_{B}:\left(B,\left.\tau_{12}\right|_{B}\right) \longrightarrow$ $\left(Y, \nu_{12}\right)$ is $G L P C^{* *}$ - continuous.

Proof. Let $V$ be a P-open set of $\left(Y, \nu_{12}\right)$. Then, $f^{-1}(V)=G \cap F$ such that $G \in \tau_{12}$ and $F$ is $g p$ - closed set in $\left(X, \tau_{12}\right)$. So, $\left.f^{-1}\right|_{B}(V)=$ $(G \cap B) \cap(F \cap B) \in G L P C^{* *}\left(B,\left.\tau_{12}\right|_{B}\right)$. By Theorem 2.2 and Corollary 2.2 we have $(F \cap B)$ is $g p$-closed set in $\left(B,\left.\tau_{12}\right|_{B}\right)$ and $(G \cap B)$ is P-open in $\left(B,\left.\tau_{12}\right|_{B}\right)$. Hence, $\left.f\right|_{B}$ is a $G L P C^{* *}-$ continuous.

\section{Remark 4.2.}

1. The composition of two GLPC-irresolute (resp. GLPC*-irresolute, GLPC ${ }^{* *}$-irresolute) functions is clearly GLPC-irresolute (resp. $G L P C^{*}$-irresolute, GLPC**-irresolute) function.

2. The composition of $g \circ f G L P C$-continuous [ resp., GLPC ${ }^{*}$-continuous, GLPC ${ }^{* *}$-continuous] function $f$ and $P^{*}$-continuous function $g$ is clearly GLPC-continuous [ resp., GLPC*-continuous, GLPC ${ }^{* *}$-continuous] function.

Definition 4.4. Let $f: X \longrightarrow Y$ be a mapping between bitoplogical spaces $\left(X, \tau_{1}, \tau_{2}\right)$ and $\left(Y, \nu_{1}, \nu_{2}\right)$. Suppose $\left(X, \tau_{12}\right)$ and $\left(Y, \nu_{12}\right)$ are supra topological spaces generated by $\left(X, \tau_{1}, \tau_{2}\right)$ and $\left(Y, \nu_{1}, \nu_{2}\right)$, respectively. Then, a function $f$ is called

1. LPO-irresolute if $f^{-1}(A) \in L P O\left(X, \tau_{12}\right) \forall A \in L P O\left(Y, \nu_{12}\right)$.

2. $L P O$ - continuous if $f^{-1}(G) \in L P O\left(X, \tau_{12}\right), \forall G \in \nu_{12}^{c}$.

Definition 4.5. Let $f:\left(X, \tau_{1}, \tau_{2}\right) \longrightarrow\left(Y, \nu_{1}, \nu_{2}\right)$ be a mapping. Suppose $\left(X, \tau_{12}\right)$ and $\left(Y, \nu_{12}\right)$ are supra topological spaces associated to $\left(X, \tau_{1}, \tau_{2}\right)$ and $\left(Y, \nu_{1}, \nu_{2}\right)$, respectively. Then, $f$ is called $G L P O$-irresolute [resp., GLPO*-irresolute, GLPO**-irresolute] if $f^{-1}(V) \in G L P O\left(X, \tau_{12}\right)[$ resp., $\left.f^{-1}(V) \in G L P O^{*}\left(X, \tau_{12}\right), f^{-1}(V) \in G L P O^{* *}\left(X, \tau_{12}\right)\right], \forall V \in G L P O\left(Y, \nu_{12}\right)$ [resp., $\left.\forall V \in G L P O^{*}\left(Y, \nu_{12}\right)\right], \forall V \in G L P O^{* *}\left(Y, \nu_{12}\right)$.

Definition 4.6. Let $f:\left(X, \tau_{1}, \tau_{2}\right) \longrightarrow\left(Y, \nu_{1}, \nu_{2}\right)$ be a mapping. Suppose $\left(X, \tau_{12}\right)$ and $\left(Y, \nu_{12}\right)$ are supra topological spaces associated to $\left(X, \tau_{1}, \tau_{2}\right)$ and $\left(Y, \nu_{1}, \nu_{2}\right)$, respectively. Then, $f$ is called $G L P O-$ continuous [ resp., GLPO ${ }^{*}$ continuous, GLPO ${ }^{* *}-$ continuous] if $f^{-1}(V) \in$ $G L P O\left(X, \tau_{12}\right)$ [resp., $\left.f^{-1}(V) \in G L P O^{*}\left(X, \tau_{12}\right), f^{-1}(V) \in G L P O^{* *}\left(X, \tau_{12}\right)\right] \forall V \in \nu_{12}^{c}$. 
Theorem 4.3. Let $f:\left(X, \tau_{1}, \tau_{2}\right) \longrightarrow\left(Y, \nu_{1}, \nu_{2}\right)$ be a mapping. Suppose $\left(X, \tau_{12}\right)$ and $\left(Y, \nu_{12}\right)$ are supra topological spaces associated to $\left(X, \tau_{1}, \tau_{2}\right)$ and $\left(Y, \nu_{1}, \nu_{2}\right)$, respectively.

1. If $f$ is $L P O$-continuous, then it is $G L P O^{*}$-continuous and $G L P O^{* *}$-continuous.

2. If $f$ is $G L P O^{*}$-continuous or $G L P O^{* *}$-continuous, then it is GLPO-continuous.

3. If $f$ is GLPO-irresolute [resp., GLPO*-irresolute, GLPO**-irresolute], then it is GLPO-continuous [resp., GLPO*-continuous, GLPO**continuous].

4. If $f$ is $P^{*}$-continuous function and $P^{*}$ - open function, then $f$ is GLPO-irresolute function, GLPO*-irresolute function and GLPO**irresolute function.

Proof.

1. Suppose that $f$ is $L P O$ - continuous. Let $V \in \nu_{12}$. Then, $f^{-1}(V)$ is locally pairwise open set in $\left(X, \tau_{12}\right)$. By using Proposition 3.1 we get $f^{-1}(V) \in G L P O^{*}\left(X, \tau_{12}\right)$ and $f^{-1}(V) \in G L P O^{* *}\left(X, \tau_{12}\right)$. Hence, $f$ is a GLPO*- continuous and GLPO ${ }^{* *}$ - continuous.

2. It is trivial by definitions. Since, every P-open set is $g p$-open set and every P-closed set is $g p$ - closed set.

3. Also can be done like no.(2)

4. Let $f$ be $P^{*}$-continuous function and $P^{*}$ open function. Suppose that $A \in G L P O^{*}\left(Y, \nu_{12}\right)$ we want to prove that $f^{-1}(A) \in G L P O^{*}\left(X, \tau_{12}\right)$. Then, $\exists F g p$-closed set and $G$ is P-open set such that $A=G \cup F$ by using Theorem 2.14 we get $f^{-1}(F)$ is $g p$-closed set and $f^{-1}(G)$ is P-open set this implies that, $f^{-1}(A)=f^{-1}(G \cup F)=f^{-1}(G) \cup f^{-1}(F)$. Hence, $f^{-1}(A) \in G L P O^{*}\left(X, \tau_{12}\right)$. Similarly, we can show that $f$ is $G L P O$ - irresolute function and $G L P O^{* *}$ - irresolute function.

Remark 4.3. The converse of Theorem 4.3 need not be true in general as shown by the following examples.

Example 4.4. Let $X=Y=\{1,2,3\}, \tau_{1}=\{X, \phi\}, \tau_{2}=\{X, \phi,\{1\}\}, \nu_{1}=\{X, \phi\}$ and $\nu_{2}=P(Y)$. Then, $\tau_{12}=\{X, \phi,\{1\}\}, \nu_{12}=P(Y)$. Take $f: X \longrightarrow Y ; f(x)=x \forall x \in X$ which is the identity function. $G L P O\left(X, \tau_{12}\right)=G L P O^{*}\left(X, \tau_{12}\right)=G L P O^{* *}\left(X, \tau_{12}\right)=P(X)$. So, $L P O\left(X, \tau_{12}\right)=\{X, \phi,\{1\},\{2,3\}\} . G L P O\left(Y, \nu_{12}\right)=G L P O^{*}\left(Y, \nu_{12}\right)=G L P O^{* *}\left(Y, \nu_{12}\right)=L P O\left(Y, \nu_{12}\right)=P(Y)$. We have $f$ is not LPOcontinuous, but it is $G L P O^{*}-$ continuous, $G L P O^{* *}-$ continuous and $G L P O^{*}-$ irresolute.

Example 4.5. Let $X=Y=\{1,2,3\}, \tau_{1}=\{X, \phi,\{1\}\}, \tau_{2}=\{X, \phi,\{1,2\}\}, \nu_{1}=\{X, \phi\}$ and $\nu_{2}=\{X, \phi,\{1\}\}$. Then, $\tau_{12}=\{X, \phi,\{1\},\{1,2\}\}$, $\nu_{12}=\{X, \phi,\{1\}\}$. Take $f: X \longrightarrow Y ; f(1)=f(3)=1, f(2)=2$. Hence, GLPO $\left(Y, \nu_{12}\right)=G L P O^{*}\left(X, \nu_{12}\right)=G L P O^{* *}\left(X, \nu_{12}\right)=P(X)$. Then, $f$ is not GLPO* - continuous but it is GLPO- continuous and it is GLPO ${ }^{* *}$ - continuous.

Example 4.6. Let $X=Y=\{1,2,3\}, \tau_{1}=\{X, \phi,\{1\}\}, \tau_{2}=\{X, \phi,\{1,2\}\}, \nu_{1}=\{X, \phi\}$ and $\nu_{2}=\{X, \phi,\{1\}\}$. Then, $\tau_{12}=\{X, \phi,\{1\},\{1,2\}\}$, $\nu_{12}=\{X, \phi,\{1\}\}$. Take $f: X \longrightarrow Y ; f(x)=x$ which is the identity function. Then, $\{2\} \in G L P O^{*}\left(y, \nu_{12}\right)$ but, $\{2\} \notin G L P O^{*}\left(X, \tau_{12}\right)$. Hence, $f$ is not $G L P O^{*}-$ irresolute but it is LPO-continuous.

On account of Theorem 4.3 and Examples 4.4, 4.5 and 4.6 we have the following corollary.

Corollary 4.2. Let $f:\left(X, \tau_{1}, \tau_{2}\right) \longrightarrow\left(Y, \nu_{1}, \nu_{2}\right)$ be a mapping. Then, we have the following diagram:

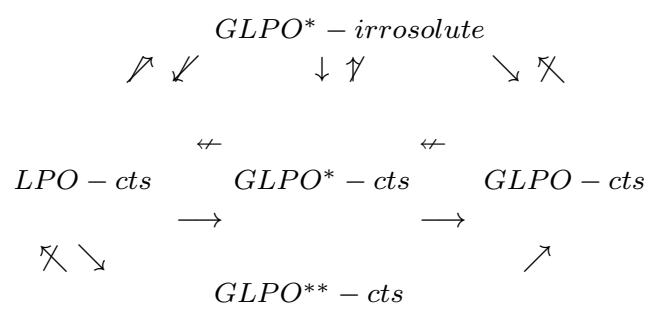

\section{Remark 4.4.}

1. The composition of two GLPO-irresolute [resp., GLPO*-irresolute, GLPO**-irresolute] functions is clearly GLPO-irresolute [resp., GLPO*-irresolute, GLPO**-irresolute] function.

2. The composition of $g \circ f$ GLPO-continuous [resp., GLPO*-continuous, GLPO**-continuous] function $f$ and $P^{*}$-continuous function $g$ is clearly GLPO-continuous [resp., GLPO*-continuous, GLPO**-continuous] function. 


\section{References}

[1] N. Levine, Generalized closed set in topology, Rend. Circ. Mat. Palermo. 19 (2) (1970), 89-96.

[2] J.C.Kelly, Bitopological spaces, Proc Lond Math Soc. 13 (1963), 71-79.

[3] A. S. Mashhour, A. A. Allam, F. S. Mahmoud and F. H. Khedr, On supra topological space, Indian J. Pure Appl. Math. 14 (1983), 502-510.

[4] A. Kandil and S. A. El-Sheikh, On bitopological spaces, first Intern.conf. on Mathematics and Statistics, Assuit University 3 (1990), 73-96.

[5] M. C. Datta, Projective bitopological spaces, Journal of the Australian Math. Soc. 13 (1972), 327-334.

[6] B.P. Dvalishvili, Bitopological spaces theory, relation with generalized algebraic structure and applications, North Holland (2005).

[7] S.A.EL-Sheikh, Dimension theory of bitopological spaces, Master Thesis, Ain Shams University, Cairo, Egypt(1987).

[8] S.A.EL-Sheikh, A new approach to fuzzy bitopologicl space, INS, 137 (2001), 283-301.

[9] M. K. Singal and A. R. Singal, Some more seperation axioms in bitopological spaces, Ann. soc. Sci. Bruelles 84 (1970), 207-230.

[10] M. Ganster and I.L. Reilly, Locally closed sets and LC-continuous functions, J. Math and math Sci. 12 (3) (1989), $417-424$.

[11] K. Balachandran, P. Sundram and H.Maki, Generalized locally closed set and GLC- continuous function. Indian J. Pure Appl. Math. 27 (3)(1996), 235-244.

[12] S.A.EL-Sheikh, Some bitopological properties via grills, International Mathematical Forum. 13 (7) (2014), 335-353.

[13] M. E. Abd-El-Monsef and E. F Lashine, Some operation on supratopological spaces, Dirasat, XIII (7) (1986), 43-50.

[14] A. Kandil, O. A. E. Tantawy, S. A. El-Sheikh and E. A. Shalaby, Generalized closed sets in bitopological spaces, South Asian J. Math. 6(2) (2016), 72-81. 